\title{
Calculation Methodology to Quantify and Classify Construction Waste
}

\author{
$\mathrm{M}^{\mathrm{a}}$ Pilar Mercader Moyano ${ }^{1, *}$, Antonio Ramírez de Arellano Agudo $^{2}$ and Manuel Olivares Santiago ${ }^{1}$ \\ ${ }^{I}$ Department of Building Construction I, University of Seville. Avda. Reina, Mercedes, 2. 41012 Seville, Spain \\ ${ }^{2}$ Department of Building Construction II, University of Seville. Avda. Reina, Mercedes, 4. 41012 Seville, \\ Spain
}

\begin{abstract}
This paper proposes a strategy to define a calculation methodology, readily available for any agent involved in the construction process. By means of this methodology we will be able to quantify and classify the construction waste generated when implementing buildings, and focuses on the dwelling sector, here referred to as Common Construction Model (CCM).

We start by quantifying the material resources consumed in the construction of this Model. Identifying, quantifying and classifying the most relevant wastes generated during the building process, future research will draw comparative analyses between the different constructive solutions and the material resources in order to minimize the environmental impact generated by the Common Construction Model (CCM).

Finally, a case study is shown where the methodology is applied on a sample of ten buildings, focuses on the dwelling sector. These buildings, on the other hand, are part of a subsidizing-housing program; both of them are defined and analysed in this paper.
\end{abstract}

Keywords: Classification of construction waste, quantification of construction waste, material resources, environmental impact, construction of buildings.

\section{INTRODUCTION}

The construction materials are the material structure in which buildings are projected and built. Its choice is one of the first areas of the architect and other agents' responsibility, as we all are conditioned by the consumption of natural resources as a source of raw materials [1].

Construction activities involved in the natural environment, use the resources of nature through the exploitation of quarries and forests, consume large amounts of energy for its conversion into construction products, change the land for the implementation of buildings and, finally, deposit residues, emissions and construction and demolition waste (C\&D waste) in the environment. This process that takes place during and at the end of the life cycle of products and works brings the resulting effect of environmental pollution.

Definitely, we can say that construction activities have a high capacity to produce waste: in receipt of products, in storage, in the areas of collection, during the process of construction, or demolition [2]. That is why the discourse on sustainability from the field of architecture, often rests on an assessment of the impact of building materials used in buildings construction and the waste that they generate [3].

The relationship between the origin and end of life cycle of building materials is direct, as the waste generated depends on the choice of material resources consumed in the implementing of the building. So, based on the analysis of

*Address correspondence to this author at the Department of Building Construction I, University of Seville. Avda. Reina, Mercedes, 2. 41012 Seville, Spain; Tel: + 34-954559893; Fax: + 34-954557018;

E-mail: pmm@us.es the environmental impact generated at the end of the life cycle of products used in construction, identifying and quantifying the waste generated on site, we encourage its prevention, reuse, recycling and other forms of recovery.

Their classification will have an adequate the construction waste $(\mathrm{CW})$ management, and will provide data related with the choice of resource material, which is one of the early stages of project management in the building project, contributing to a sustainable development in the construction activity in application of the Royal Decree 105/2008 of February 1 [4].

In this line of environmental commitment, there is a need to identify and quantify the construction waste generated in the buildings that we design, build and live in; beginning with the identification and quantification of material resources consumed in the construction of its elements.

\section{MATERIALS AND METHODOLOGY}

Consistent with previous arguments raised here, this paper aims to set up a calculation methodology to quantify construction waste generated in the construction of buildings construction, defined here as blocks of flats for Subsidized Housing, which allows us to identify and classify the construction waste more relevant generated.

To achieve the proposed goal, we must develop a structure (see Fig. (1)) supported by three hierarchical levels, based on the temporal priority in their achievement:

In Level 1, the objective is to select a sample of buildings whose construction and typological characteristics are representative of the residential buildings, intended for statesubsidized housing in Seville, which we will call Common Constructive Model (CCM). 


\section{OBJECTIVES}

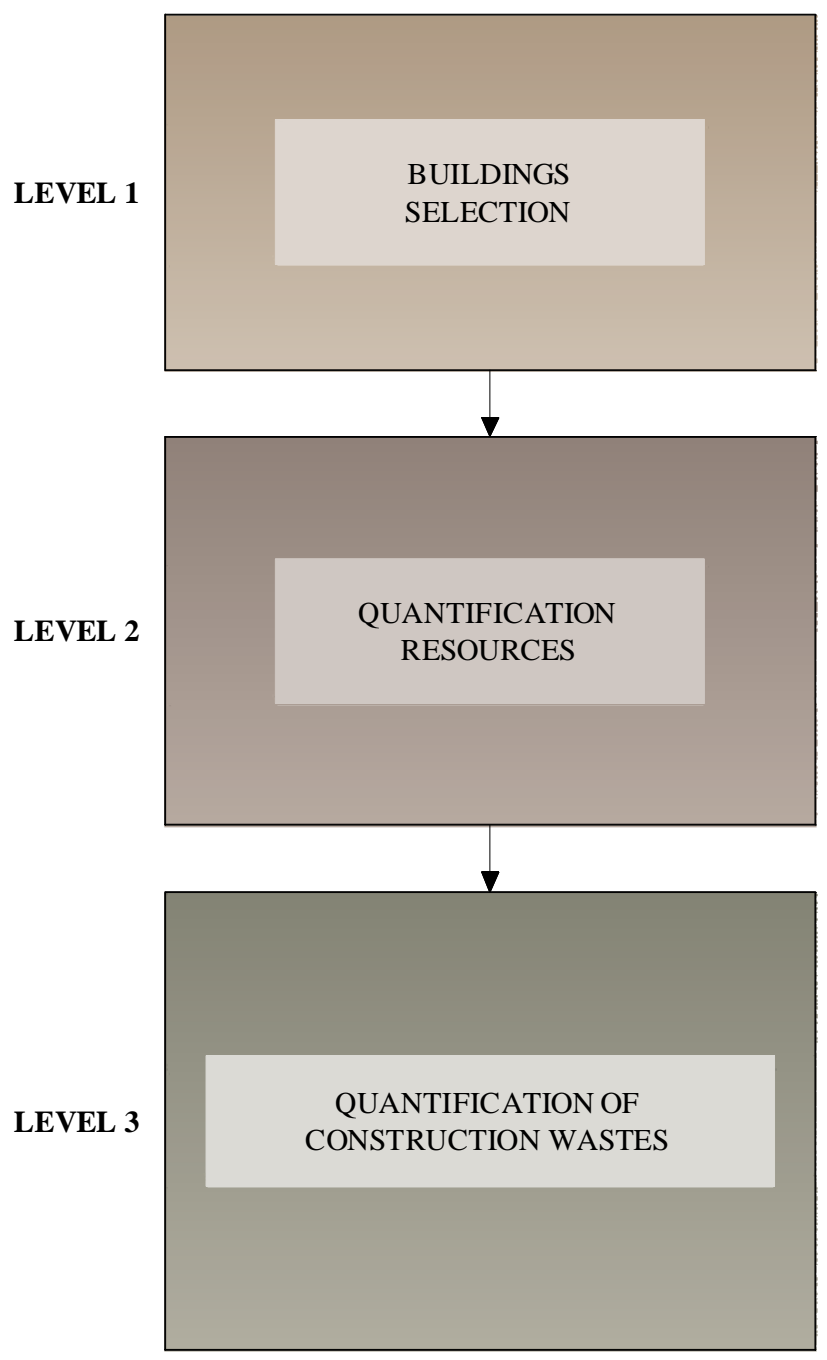

Fig. (1). Hierarchy of objectives.

Level 2 aims to quantify, in $\mathrm{kg}$ per square metre, the material resources consumed in implementing a constructive model in the sample selected in the previous level.

The identification and quantification of the material resources used in the sample chosen for this study, will in turn allow us, in Level 3, to identify, qualify and quantify the construction waste generated in the implementation of the $\mathrm{CCM}$, as a result of the physical resources consumed during its construction.

The following structure (see fig. (2)) is established to fulfil the objectives at each level, regarding the following plan of steps:

\section{Step 1}

Study the construction sector to define the Common Constructive Model (CCM), the one that represents "fashion" and select a study sample -representative of the usual construction system.
This will need to present three sub-steps, the first one (S11), aims to achieve the knowledge of the architectural reality, which results in the study of current common building model.

In the second one, (S12) the aim is to define the constructive model, because models differ according to the climate zones where they are located and we want to implement our calculation methodology. Specifically, we will apply it to the most representative building type, i.e., the buildings designed to meet the required living conditions of a continental Mediterranean climate with variable rainfall, very hot dry summers and mild winters, an average annual temperature of $18.6^{\circ} \mathrm{C}$ and rainfall of $534 \mathrm{~mm}$ per year.

In the third one (S13), the study sample is chosen. It involves ten projects that meet the performance characteristics of the model defined in the previous sub-step, specifying its morphological and constructive characterization according to those residential buildings destined to Subsidized Housing, partially subsidized by the public administration. The composition, programs and rooms of these buildings are generally preset as follows:

- $\quad$ The housing has at least one living room, a dining and a kitchen, a bedroom and a bathroom.

- In homes of more than $70 \mathrm{~m}^{2}$, there will be, at least two toilets.

- $\quad$ Floor space. For each type of housing, by number of bedrooms, is specified as in Table $\mathbf{1}$ below

Table 1. Programs Subsidized Housing

\begin{tabular}{|l|c|}
\hline \multicolumn{1}{|c|}{ Housing: } & Maximum Usable Area $\left(\mathbf{m}^{2}\right)$ \\
\hline \hline One bedroom & 60 \\
\hline Two bedrooms & 70 \\
\hline Three bedrooms & 90 \\
\hline Four or more bedrooms & $\begin{array}{c}\text { The maximum allowed in those programs for } \\
\text { areas larger than } 90 \mathrm{~m}^{2} .\end{array}$ \\
\hline
\end{tabular}

\section{Step 2}

Quantify, in kg per square metre, the material resources consumed in implementing a constructive model in the selected sample.

It will require the development of three sub-steps, the first one, (S21), will homogenize the measurements of the selected projects; the second one, (S22), will convert the results in quantities of $\mathrm{m}^{2}$ built, the third one, (S23) will normalize the above values by weight per $\mathrm{m}^{2}$ built, it is designed to provide comparable results. It is achieved by defining the reference frame of the Model.

\section{Step 3}

Quantify, in kg per square metre, the waste generated by the CCM, the result of material resources consumed, classifying them according to their selective separation according to limits set out in the National Decree 105/2008. 


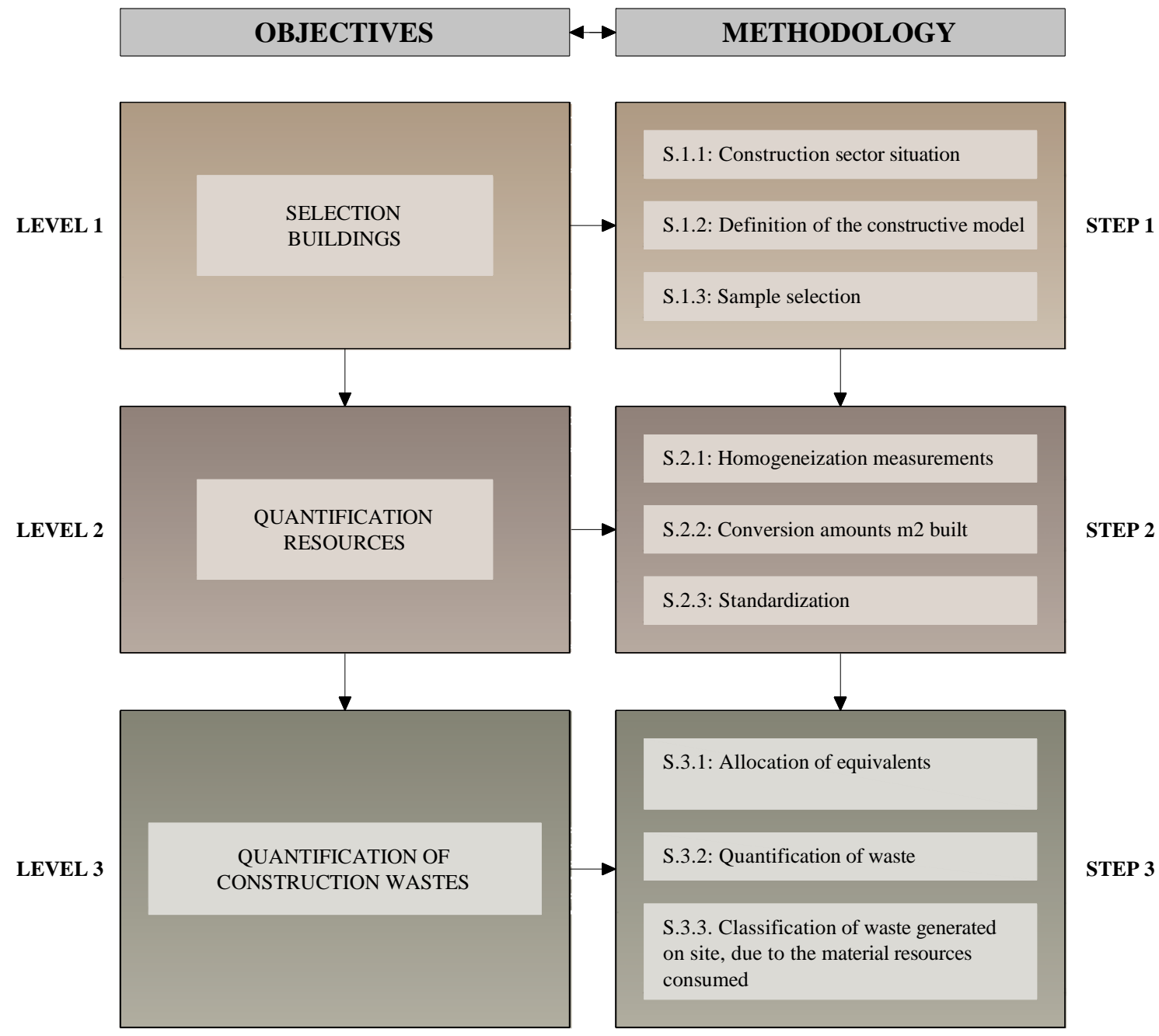

Fig. (2). Methodological Scheme.

In the first sub-step (S31), the strategy implemented to achieve our goals will be to establish a set of hypotheses that allow us to adapt the environmental information available, the bank BEDEC PR/PCT of ITeC [5], to our list of material resources consumed in the construction of the CCM, getting the waste generated per $\mathrm{kg}$ of material resource.

In the second sub-step (S32), we intend to quantify the waste generated by the consumption of material resources, expressed in kilogram per square metre $\left(\mathrm{kg} / \mathrm{m}^{2}\right)$ of built-up area. To accomplish this, we will need to multiply the total amount of material resources consumed by each of the waste products generated in the construction site.

Parallel to the quantification of waste generated in the $\mathrm{CCM}$, as a result of physical resources consumed in its implementation, the application is tested on a sample of ten projects representing the same construction, identifying, at the same time, the waste generated on site due to material resources consumed in their implementation, which is achieved by sub-step (S33).

\section{RESULTS}

In this section we carry out the structure proposed in this paper, following the hierarchical order of steps in the plan in (see Fig. (2)), as follows:

\section{Step 1}

The objective at Level 1 is to select a sample of buildings whose construction and typological characteristics are representative of the CCM, which is achieved by performing the following substeps:

\section{Step 1.1. Construction Sector Situation}

It must be viewed in the context of the current construction circumstances, to understand these circumstances and to intervene constructively and identify the building type that represents "the fashion" in the construction sector.

From statistical publications issued by the Ministry of Development [6] from 2004 until the present day, we get the usual type of construction: The most usual type of building is a new building for residential use, consisting of four floors above ground and one below ground, so that the study of CCM should focus on this type of building.

\section{Step 1.2. Definition of the Common Construction Model (CCM)}

The construction model defined in this stage, called Common Construction Model (CCM), is the one defined in 


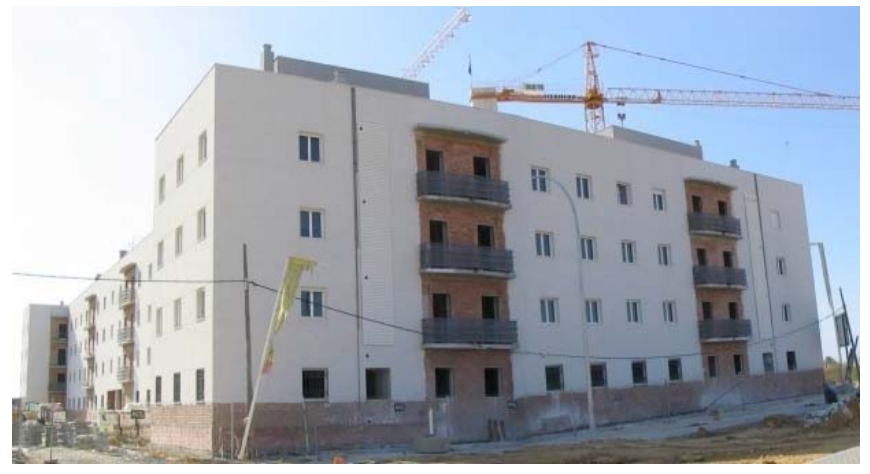

Fig. (3). Common Constructive Model (CCM), illustrative image.

the model of the consumed construction resources quantification [7], which is taken from the field work carried out in the Licensing Planning Service for the Planning Department of Seville, because it has the climatic features defined for this study. This work is a detailed analysis of all the implementation projects for newly-constructed residential buildings that requested building permits in recent years (2003-2010), using the computer program known as Integrated Management of Records (Gestión Integrada de Expedientes, GIE) and the council archives.

The model chosen is one whose "constructive morphology", i.e. geometry, plot organization, typology, solutions, systems and construction materials used for its implementation, is consistent with the most commonly used in current buildings, and its definition is as follows:

The typology of these buildings is made up of a block of four upper floors and a basement, with a provision on free plot, closed block geometry with inner courtyard. Floor area is around $11.000-12.000 \mathrm{~m}^{2}$ and they have a total of $82-86$ state-subsidized houses, with the dimensional characteristics defined in previous sections.

The structural characteristics of this type are: reinforced concrete slab foundation, vertical structure of concrete pillars with wrought-way, flat roof, cladding ceramic brick and steel exterior carpentry.

\section{Step 1.3. Sample Selection}

Ten state-subsidized housing blocks are selected for the study; they are representative of CCM, with similar geometric construction and design, so that the results can be considered representative of the construction model here considered. as is shown in (see Fig. (3)). They are located in the Pino Montano Distgrict and the planning that develops it is called SUP-PM-6. It was also established that it is in this area where the $98 \%$ of the state-subsidized housing buildings are constructed in Seville.

\section{Step 2}

It is quantified in $\mathrm{kg}$ per square metre of built up area $\left(\mathrm{kg} / \mathrm{m}^{2}\right)$ of material resources consumed in the implementation of the building model established in this work, according to the data afforded by the basic elements that constitute the building blocks and form part of the measurements in the ten projects of the selected sample.
This document contains a list of basic materials quantified in different units of measurement that best fit their shape and their intended use in the construction site.

Therefore, from the information provided by the measurements in the plans for the implementation of the ten selected buildings, we extract the data needed to quantify in a meaningful way the amount in $\mathrm{kg}$ of different materials, by applying the Transfer Measurement software to "translate" the materials information presented by the measurements.

The application of the quantification model is performed using a frame of reference as instrumental support a frame of reference. This process is organized in the following substages:

\section{Step 2.1. Standardization of Measurements}

All the construction works must be given a structure to organize data, common to all of them, to enable the clear identification of the wasted resources and facilitate the comparative analysis, using the field transfer measurement, extending its scope to the list of basic materials and considering the classification and coding [7] system proposed by the Andalusian Construction Cost of Database (ACCD). The software used for this calculation is the Measurement and Budget Calculation Program [8] "Presto V.8.8".

Based on data from the measurement items, we find the components of the units and we can determine the amount of each component in each of the studied projects, from a list of wasted resources in each of the projects studied here, decomposed in the measurement units used in the ACCD.

\section{Step 2.2. Conversion of Amounts Per m2 of Built up Areas}

We obtain the amounts of waste materials per $\mathrm{m}^{2}$ of construction, for each of the selected buildings, by dividing the amount of each basic element determined for each project, measured in original measure units, by the built up area, thus correcting the negative effect of the size of the work and enabling comparisons between them.

\section{Step 2.3. Standardization}

The standardization of the resulting units refers to the transformation of the unit of origin, -a unit of measurement of the elements-, into the target unit, -the weight in $\mathrm{kg}$ of the elements. To enable comparable results, we use the so-called Transformation Coefficients, "Tc", as support, which supposes the weight by the element reference unit and the transformation of the measurement criteria of the point of origin, into the measurement criteria for the target item $\left(\mathrm{kg} / \mathrm{m}^{2}\right)$. It is used when the unit of measurement of the item is different from the $\mathrm{kg}$ measurement.

In order to determine the weight, it has been necessary to characterize the basic sample materials, in some cases according to the project, in others in-sit, or according to mandatory regulations and ultimately through the definition of quality control companies and specialized laboratories or by applying the process of calculating the number of components per unit of measurement established in the Budgeting Works book [2]. 
To determine the Transformation Coefficients, "Tc", we have taken four types of information sources:

- Source 1: Bulk density. The weight of the basic material component is obtained by applying the bulk density.

- Source 2: Sample weight in scale. The basic material component specified and defined in the project, is weighted in a scale at the supply place.

- Source 3: Commercial Information. The weight of the component is obtained through information provided by commercial catalogs of products, being necessary, in this case, to fully characterize the basic sample materials [2] and go to three different commercial firms to obtain the arithmetic mean of its values.

- Source 4: Weight subjective estimate. In the event that the complexity of the item make it impossible to obtain its weight using the above sources, a subjective estimate of the weight is made, by weight similarity of homologous elements.

It is necessary to consider the following:

Each of the sources is used when it is impossible to determine the weight of the item with the immediate previous source.

If the specifically defined sample project cannot be found, we proceed to obtain the data of the weights of up to three samples, similar to the requested one, with the "Tc" value corresponding to the arithmetic mean of the results obtained.

Since the values for the weight of the item may vary depending on the trademark, and this is not usually mentioned in the project, in case of using Source 3, we may use a maximum of three weights related to samples of different trademarks with similar features, for the same product, being the value of "Tc" the average of the values obtained, ignoring the most different one.

For example, the value obtained through source 2 is given for a slip latch without safety lock, a sample weighed in the scales in "Andalucía S.A fittings" company, results in a "Tc" value of $0.256 \mathrm{~kg} / \mathrm{u}$, arithmetic mean of the three trademarks: AZBE, AMIG and MCM.

The application of "Tc" to each basic material component, will provide:

a. The $\mathrm{kg}$ of each basic material component consumed per $\mathrm{m}^{2}$ of construction, obtaining the minimum, average and maximum values of the sample.

b. The Kg of construction waste consumed in each project in the sample.

c. The average weight of construction waste per $\mathrm{m}^{2}$ of building at the CCM.

The standardization of units of measurement leads to the quantification of waste materials in the CCM, expressed in $\mathrm{kg} / \mathrm{m}^{2}$ of built area.
We come to the conclusion that, with this stage, the waste materials consumed in implementing the defined CCM, gives a total of $2177.738 \mathrm{~kg} / \mathrm{m}^{2}$ of built up area [10].

Depicting the results in a graph (see Fig. (4)), we can observe in percentages, the most important Basic Material Component (BMC) consumed in the sample and, therefore, the more frequently used material resources, resulting as follows:

\section{Step 3}

It is quantified in $\mathrm{kg}$ per $\mathrm{m}^{2}$ of built up area, the Construction Waste $(\mathrm{CW})$ generated in the implementation of the building model established in this work, CCM, as a result of waste resources consumed in its implementation.

This stage has the task of selecting the Basic Material Component (BMC) that create more construction waste in the implementation of the CCM, as well as classifying and quantifying them, according to the building materials referenced in the selective separation established by Royal Decree 105/2008 [4] and that are the following: Concrete, bricks, tiles, ceramic, metal, wood, glass, plastic, paper and cardboard.

\section{Step 3.1. Allocation of Equivalents}

The methodology consists in establishing a number of hypothesis that allow us to adapt the environmental information available. The set of databases with environmental information are called the METABASE of ITeC [5], we accept like a reliable source of information, the list of material resources consumed in implementing the CCM, creating with them a database that allows us to know each BMC of the sample, the amount of construction waste $(\mathrm{CW})$ generated on the construction, per $\mathrm{kg}$ of material resource used, and waste generation separation based on selective exposure.

With the identification and quantification of $\mathrm{CW}$ generated per each BMC consumed, we can quantify the total amount of $\mathrm{CW}$ generated in the implementation of the CCM.

Accordingly, this paper develops a methodology for quantifying a model of waste generated in the CCM residential buildings, whose design responds to the demands required by a Mediterranean climate and the housing program which are identified with those specified for subsidized housing in the preceding paragraphs, from the standpoint of material resources consumed in its implementation, which are the source of the waste.

The process is as follows:

We start at this stage the list of material resources consumed in implementing the CCM, which constitute the reference frame of the model, broken down in detail in Annex XVI of Volume II of the doctoral thesis entitled "Quantification of the resources consumed and $\mathrm{CO}_{2}$ produced in the construction of Andalusia and its implications for the Kyoto Protocol [10]. 

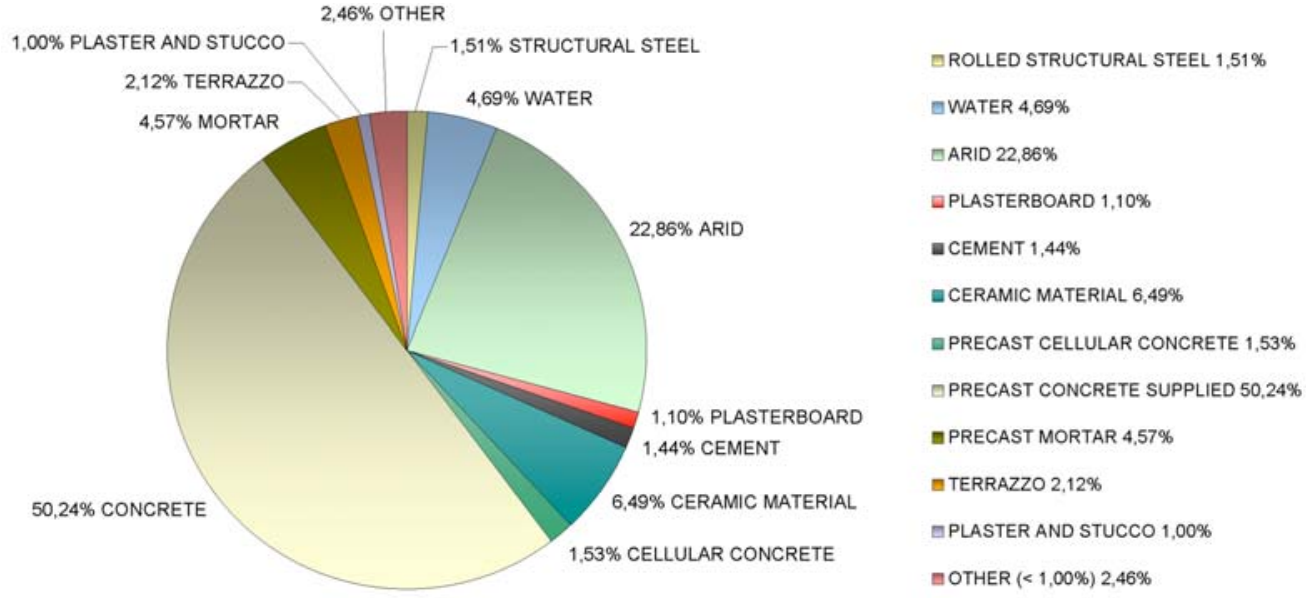

Fig (4). Representation of weight in the CCM of the main BMC consumed.

Obtaining the set of "rules" that will justifiably synthesize the representative BMCs of the sample.

To get general "rules", we need to define the common parameters that will identify each of the BMCs of the sample, so it is necessary to know the characteristics, behaviour and way of evolution of the system variables in relation to the objectives set at this level 3, that is, the raw materials that are consumed, and ultimately the origin of the waste items generated.

Once the most representative Basic Materials Components have been selected in the implementation of CCM and the values, that are defined by weight per $\mathrm{m} 2$ built. It is necessary at this stage to determine the environmental parameters for the waste generated by each basic component used.
The aim is to create a specific environmental database for the CCM representative of the BMCs in Seville, which is available in the next stage of the methodology.

To define the set of rules that allow us to bind the BMCs to form the image of the Reference Model with the Environmental Data Base of the ITeC, -from which we will take the information regarding the waste generated by the specified building materials-, it will be necessary a strategy to transform the "inputs" in "outputs". This consists in the analysis of the physical and chemical features of all the variables, specifying the structure of each BMC, this is, the raw material that is the reference material, allowing us to establish a set of assumptions that enables us to allocate the available environmental values considered equivalent.

Table 2. Construction Wastes Generated in the Work Setting Material Resources Consumed in the Construction of the CCM

\begin{tabular}{|c|c|c|c|c|c|c|c|c|}
\hline \multicolumn{9}{|c|}{ CW Generated in the Construction of CCM (in Kg of Material) } \\
\hline $\mathbf{H}_{\mathrm{i}}$ & $\begin{array}{c}\text { BMCs } \\
\text { Representatives of } \\
\text { CCM }\end{array}$ & Concrete & Ceramics & Metal & Wood & Glass & Plastic & $\begin{array}{l}\text { Paper and } \\
\text { Cardboard }\end{array}$ \\
\hline $\mathrm{H}_{\mathrm{i}, \mathrm{a}}$ & $\mathrm{BMC}_{\mathrm{a}}$ & $\begin{array}{c}\mathrm{Kg} \\
\text { Concrete }_{\mathrm{a}}\end{array}$ & $\begin{array}{c}\mathrm{Kg} \\
\text { Ceramics }_{\mathrm{a}}\end{array}$ & $\begin{array}{c}\mathrm{Kg} \\
\text { Metal }_{\mathrm{a}}\end{array}$ & $\begin{array}{c}\mathrm{Kg} \\
\text { Wood }_{\mathrm{a}}\end{array}$ & $\begin{array}{c}\mathrm{Kg} \\
\text { Glass }_{\mathrm{a}}\end{array}$ & $\begin{array}{c}\mathrm{Kg} \\
\text { Plastic }\end{array}$ & $\begin{array}{c}\mathrm{Kg} \\
\text { Paper/ } \\
\text { Cardboard }_{\mathrm{a}}\end{array}$ \\
\hline & & 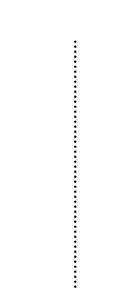 & & & & & & 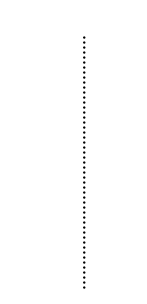 \\
\hline $\mathrm{H}_{\mathrm{i}, \mathrm{z}}$ & $\mathrm{BMC}_{\mathrm{z}}$ & $\begin{array}{c}\mathrm{Kg} \\
\text { concrete }_{\mathrm{a}}\end{array}$ & $\begin{array}{c}\mathrm{Kg} \\
\text { ceramics }_{\mathrm{a}}\end{array}$ & $\begin{array}{c}\mathrm{Kg} \\
\text { metal }_{\mathrm{a}}\end{array}$ & $\begin{array}{c}\mathrm{Kg} \\
\operatorname{wood}_{\mathrm{a}}\end{array}$ & $\begin{array}{c}\mathrm{Kg} \\
\text { glass }_{\mathrm{a}}\end{array}$ & $\begin{array}{c}\mathrm{Kg} \\
\text { plastic }_{\mathrm{a}}\end{array}$ & $\begin{array}{c}\mathrm{Kg} \\
\text { Paper/ } \\
\text { cardboard }_{\mathrm{a}}\end{array}$ \\
\hline
\end{tabular}


The assumptions established are:

- Hypothesis 1: Basic Materials Components consisting of pure raw material. This hypothesis will apply to those representative basic material components, where we can easily identify the pure raw material. In this case the corresponding values for the waste generated from such materials are relevant to such pure raw material.

- Hypothesis 2: Basic Material Components of composite materials. The BMCs are made of different materials. In this hypothesis we will apply the environmental values in terms of waste generated for each of the BMC elements of the material, the same percentage involved in weight.

- Hypothesis 3: Basic Materials Components equivalents. This hypothesis is applied to those representative BMCs samples whose physicochemical characteristics are not explicitly defined in the original project. In this case, we assume that the raw material that composes it is a material equivalent to those in the list of the environmental values, of the Catalonia Institute of Construction Technology (ITeC) assigning, consequently, the classification and quantification established for the generated construction waste.

- Hypothesis 4: Basic Materials Components not relevant to the investigation. The BMCs whose decomposition into its constituent elements do not provide relevant environmental information, related to the construction waste they generate, are supposed to behave like the mean, ignoring the process.

The results obtained are summarized in the so-called Matrix of equivalence of environmental data, setting out in detail the construction waste generated, in weight $(\mathrm{kg})$, for each BMC sample and the amount generated.

This matrix of information that is in turn in itself a Database of environmental information in relation to the BMCs representative of the CCM, has the following configuration (Table 2):

Where the columns of the matrix show the following:

$\mathrm{C} 1=$ column which specifies the hypothesis $(\mathrm{Hi})$ applied to the Basic Material Component (BMC) that accompanies the allocation of equivalence assigned. Where $\mathrm{i}=1,2,3, \ldots$, 5 .

$\mathrm{C} 2=$ column which represents the (BMCs) CCM representative defined in alphabetical order.

$\mathrm{C} 3=$ column corresponding to the values of concrete waste generated by the BMC they go with, expressed in $\mathrm{kg}$

$\mathrm{C} 4=$ column corresponding to the values of waste bricks, tiles, ceramics, generated by the BMC they go with, expressed in $\mathrm{kg}$.
$\mathrm{C} 5=$ column corresponding to the values for metal waste generated by the BMC they go with, expressed in $\mathrm{kg}$

C6 $=$ column corresponding to the values of wood waste generated by the BMC they go with, expressed in $\mathrm{kg}$.

$\mathrm{C} 7=$ column corresponding to the values of glass waste generated by the BMC they go with, expressed in $\mathrm{kg}$.

$\mathrm{C} 8=$ column corresponding to the values of plastic waste generated by the BMC they go with, expressed in $\mathrm{kg}$

C9 $=$ column corresponding to the values for paper and cardboard waste generated by the BMC they accompany, expressed in $\mathrm{kg}$.

Step 3.2. Quantification of Construction Waste by Weight Per Square Meter. (Convert Weight “kg” to Area “m2")

The next step is to apply the equivalences obtained in the previous section to each basic material component, which will permit get:

- $\quad$ The $\mathrm{kg}$ of each basic material component becomes the construction waste per $\mathrm{m}^{2}$ of build-up area and type of waste generated.

- $\quad$ The total $\mathrm{kg}$ of construction waste generated in the construction of the CCM, obtained as the summation of the classification of different residues identified.

- $\quad$ The average weight of construction waste generated per $\mathrm{m}^{2}$ of building at the CCM.

- Material resources that generate more construction waste in the implementation of the CCM.

The results are given in the so-called Standardized Generated Waste Matrix (QWN), whose shape is expressed as follows (1):

$\mathrm{Qw}=\left[\mathrm{Q} \mathrm{wN}_{\mathrm{s}}\right]$

Where:

QwNp, s = standard amounts, $\mathrm{kg}$ of construction waste generated per square meter of built-up area, for each Basic Material Component (BMC) used in the implementation of the CCM. The matrix is broken down as follows (Table 3):

Where:

A A N N N N k $=$ Is the code for the Basic Material Component (BMC) in the sample to which it relates. Presents the scheme of Andalusia Construction Costs Database, ACCD, this code is formed by seven characters, the first two alphabetic and the remaining five numeric, which are added after the last digit number, letter " $k$ ", to express that the values it represents are in $\mathrm{kg}$.

$\mathrm{QN}_{\mathrm{S}}=$ Standard amounts, $\mathrm{kg}$ of construction waste generated in the implementation of the CCM per square meter of built-up area, for each basic material component of the sample material (BMC). 
Table 3. Matrix of Construction Waste Generated

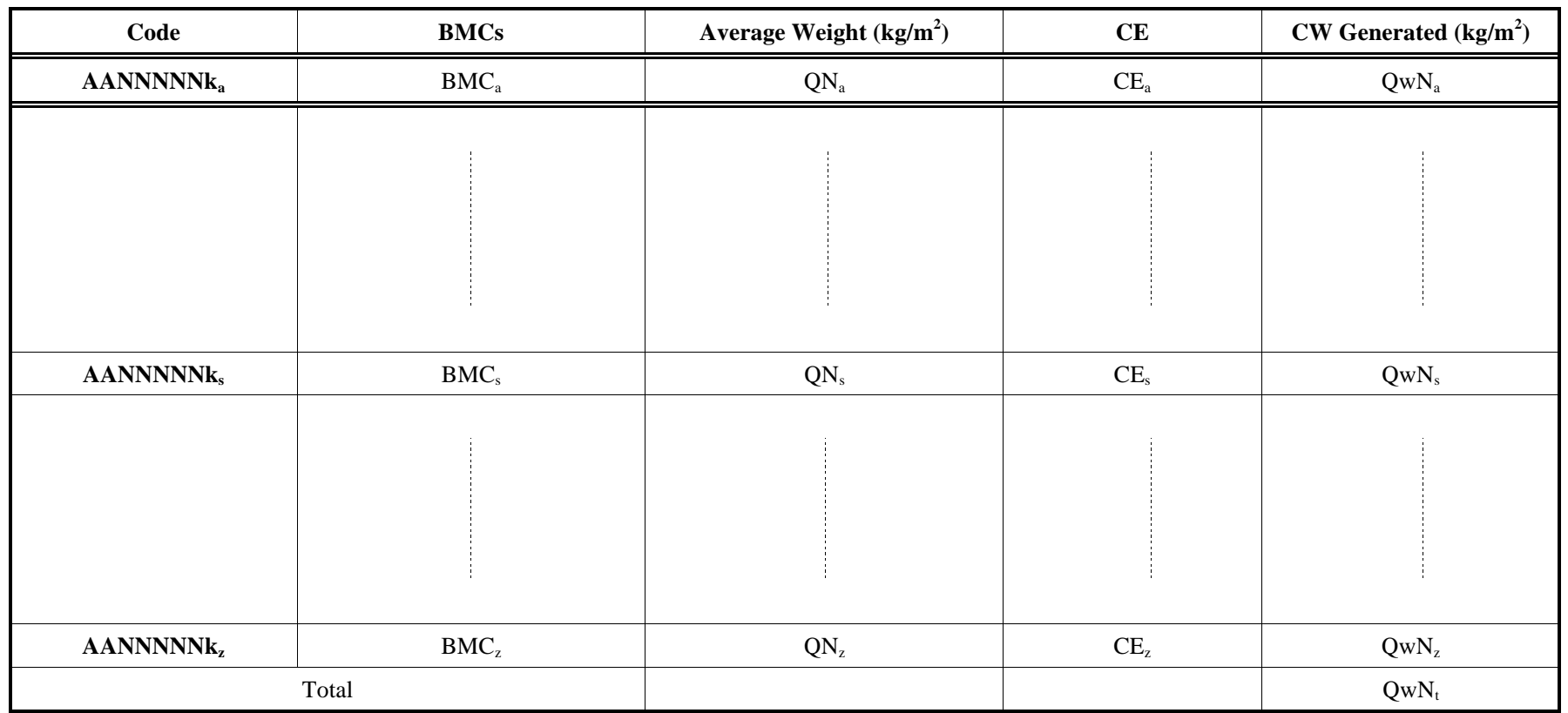

$\mathrm{CE}=$ Coefficient to measure the construction waste generated in the process, for each BMC, from the packaging used in transport as environmental information provided by the Database of ITeC BEDEC [5].

QwN $\mathrm{w}_{\mathrm{s}}=$ Standard amounts, in $\mathrm{kg}$ of construction waste per $\mathrm{m}^{2}$ of built-up area, generated by the material resources consumed in the implementation of the CCM.

The last row contains the following totals values:

Total $=\Sigma \mathrm{sQwN} s(\mathrm{~s}=\mathrm{a}, \ldots . . ., \mathrm{z})$

Where the concept of "total" includes all the values corresponding to the $\mathrm{kg}$ of construction waste generated by the BMCs consumed in the implementation of the CCM per square metres $\left(\mathrm{m}^{2}\right)$ of built-up area. The final results are collected in the following Table $\mathbf{4}$, where the different waste generated are measured in $\mathrm{kg}$ per square metres of built-up area $\left(\mathrm{kg} / \mathrm{m}^{2}\right)$, involving a total of $6.89 \mathrm{~kg} / \mathrm{m}^{2}$ of built-up area in the defined CCM .

\section{Step 3.3. Classification of Construction Waste Generated by the Material Resources Consumed in the Implementation of the CCM}

After identifying the most important building materials employed in the implementation of the defined model, we quantified the waste generated in their assembling, by applying known data bases, taken as reliable sources of information, and a calculation methodology has allowed its adaptation to our list of material resources consumed and used.

From the results obtained in the previous stage we can make a first classification of the construction waste generated in the implementation of the defined CCM, based on their danger, observing that the $97.73 \%$ of construction waste generated are considered non-danger waste, while the 2. $27 \%$ are hazardous waste by its toxicity, mainly from paints, enamels, varnishes, primers, release agents, fillers and solvents, which will appear graphically as shown (see Fig. (5)).

If we do a breakdown of the waste included in the previous figure, (see Fig. (6)), we see the percentages for the different waste generated from packaging -mainly those used to transport the most usual building materials used in the implementation of the defined CCM.

The classification established in the database BEDEC of ITeC, adds to the waste classification established by the Royal Decree 105/2008, which regulates the waste production and management from construction and demolition, the waste and mixed metals, which represent a minimum percentage of the total, $1.31 \%$ of non-hazardous

Table 4. Quantification of Construction Waste Generated in the Implementation of the CCM

\begin{tabular}{|c|c|c|c|c|c|c|}
\hline \multicolumn{7}{|c|}{ Construction Waste Generated by the Resources Consumed in Implementation of the CCM (kg/m2) } \\
\hline \multicolumn{6}{|c|}{ Non Hazardous } & Hazardous \\
\hline Wood & $\begin{array}{c}\text { Packaging } \\
\text { Carton-Paper }\end{array}$ & Concrete & Metal Mixed & Plastic & Waste Mixed & \\
\hline 5.82243 & 0.67353 & 0.0365 & 0.08514 & 0.05065 & 0.00549 & 0.15669 \\
\hline \multicolumn{7}{|c|}{ Total construction waste generated $=6.89756 \mathrm{~kg} / \mathrm{m}^{2}$ built } \\
\hline
\end{tabular}




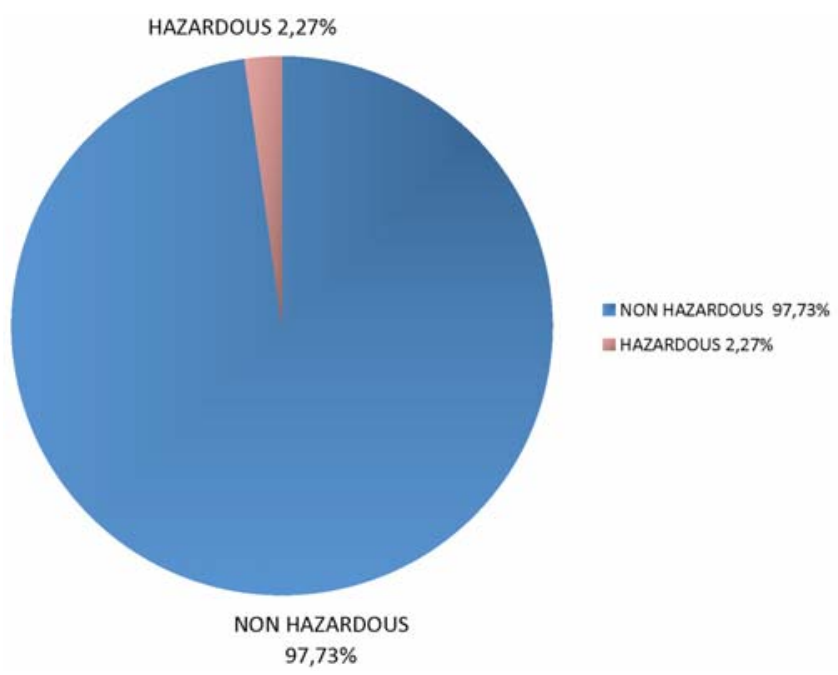

Fig. (5). Classification of construction waste generated in the implementation of the CCM according to hazard.

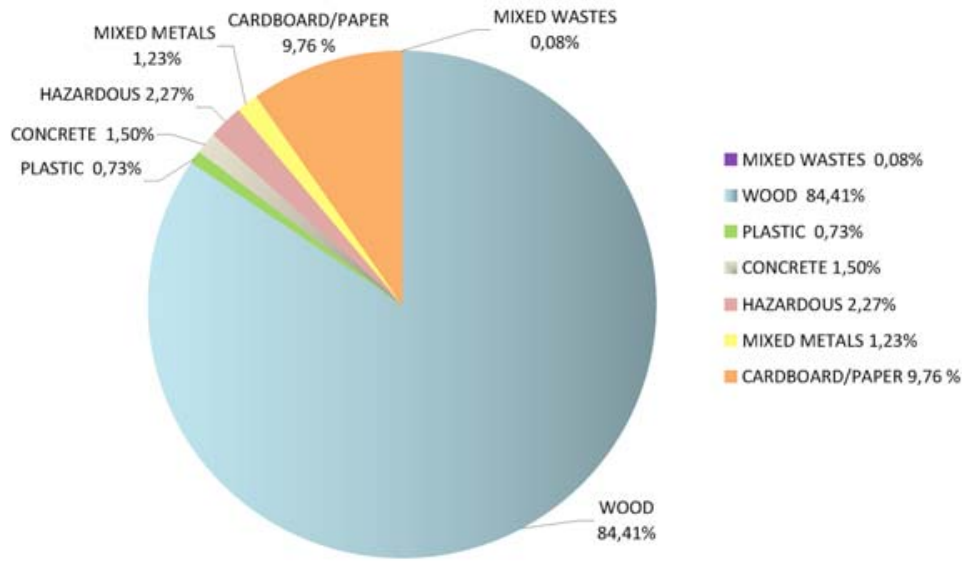

Fig. (6). Representation Construction Waste generated in the implementation of the CCM.

waste, but given its composition we consider important to reflect here. Mixed waste residues are related to those mixed residues from construction and demolition that do not contain mercury or dangerous substances and cannot be assigned to any of those identified by the Royal Decree $105 / 2008$.

It is noted that the wood waste from pallets on which building materials are transported, represent the largest percentage of generated waste, with $84.41 \%$ from the $97.73 \%$; they are part of the not hazardous waste generated on site.

The results are in themselves the evidence of our need to consider how to minimize construction waste generated during construction, showing up, at the same time, those material resources which we must insist to be taken care of during their transport and implementation and how we can proceed to obtain a more sustainable lifestyle through the construction of our buildings, through the reuse, recycling and/or recovery of generated waste and, perhaps, even replacing the -currently- most usual packing materials.

\section{CONCLUSIONS}

In detail, it has been possible to draw the following conclusions:

\section{Related to the Generated Quantification Model}

The quantification model created has fulfilled the main objective: the quantification of construction waste generated in the construction of residential buildings destined to subsidized housing, arising from the use of building materials consumed in its implementation and the construction waste generated.

The methodology allows the homogeneous selection of representative Common Construction Model (CCM) of residential buildings, defined here as blocks of flats for Subsidized Housing. It is also extensible to any geographical area and building typology.

It can quantify the construction waste generated in the implementation of CCM, with a high level of definition and closeness to the reality of the works, by using the Transfer of Measurement of projects implementation, as a tool to facilitate specific development of the quantification of the waste generated based on the quantification of the material resources consumed.

It is presented as a user-friendly methodological tool, an alternative to specialized software, designed to serve in the research of generated construction waste, so as to enlarge the existing supply of tools. 


\section{Related to the Implementation of the Quantification Model to the CCM}

The test model quantification of generated construction waste on the sample of ten projects representative of residential construction destined to subsidized housing has enabled the identification of the waste generated in its contruction, and the percentage they occupy in the construction per square metre of built-up area for each Basic Material Component (BMC) in the sample, identifying the most relevant.

The results obtained for CCM, represent a reference model for testing new projects that aim to minimize the environmental impact generated by the CCM as a result of the construction waste generated in its implementation.

The quantification of the construction waste produced and the origin of the materials that enable architects to rethink their use in the design phase. The results show once again the sustainable alternative to the use of prefabricated materials.

This paper is presented as a calculation tool that enables the reader to know a diagnosis of current constructions which is in a constant struggle with the environmental architecture, from the standpoint of construction waste generated by the resources materials consumed in the construction of our buildings, so as to establish a Reference Image which will be useful to test different alternatives to the conventional building subsystems, -defined as conventional- and test their efficiency, that is, the minimization of natural resources consumption in manufacturing building materials and the impact that they have lay through the construction waste generated from its use.

\section{ACKNOWLEDGEMENT}

None declared.

\section{CONFLICT OF INTEREST}

None declared.

\section{REFERENCES}

[1] A. Cuchí Burgos, and G. Wadel, "The energy efficiency guide for property managers", ${ }^{\text {st }}$ ed. Barcelona, Spain, 2007.

[2] A. Ramírez de Arellano Agudo, "Giving a Construction Estimate", $4^{\text {th }}$ ed. Seville University, Seville, Spain, 2010.

[3] A. Cuchí, "Architecture and sustainability". Polytechnic University of Catalonia, Barcelona, Spain, 2005.

[4] Spanish Government - Ministry of the Presidency, 2008. "National Decree 105/2008, 1 February, which Regulates the Production and Management of the Construction and Demolition Waste". Edited by Ministry of the Presidency, Spanish Government, 2008.

[5] Database Construction Elements, Catalonia Institute of Construction Technology, 2000. Database. http://itec.es/nouBedec.e/presentaciobedec.aspx . database date: 06/11/2010.

[6] Spanish Government-Ministry of Development: "Construction and housing:1990-1998", Madrid, Spain, 1999; "Construction and housing:1994-1999", Madrid, Spain, 2000; "Construction and housing:1998-2003", Madrid, Spain, 2004; "Construction of buildings 1999-2004", Madrid, Spain, 2005; Construction of buildings 2003-2007, Madrid, Spain, 2008.

[7] P. Mercader Moyano, M. Marrero, J. Solís Guzmán, M.V.Montes Delgado, A. Ramírez de Arellano, "Quantification of material resources consumed during concrete slab construction", Construction Reports-Informes de la Construcción, vol. 62, no. 517, pp.125-132, 2010. DOI: 10.3989/ic.09.000

[8] Andalusian Construction Cost Database, 2009. Database. http://www.juntadeandalucia.es/obraspublicasyvivienda/portalweb/web/areas/vivienda/texto/bcfbb3af-ee3a-11df-b3d321796ae5a548 database date: 15/11/2010.

[9] AAVV., "Construction Cost Manual, PRESTO V. 8.6", Edited by Soft S.A, Madrid, Spain, 1999.

[10] M.P. Mercader Moyano, "Quantification of the resources consumed and of $\mathrm{CO}_{2}$ emissions on the construction sites of Andalusia and its implications for the Kyoto Protocol". Ph.D. thesis, Seville University, Seville, Spain, May 21, 2010. Database. http://fondosdigitales.us.es/tesis/tesis/1256/cuantificacion-de-losrecursos-consumidosy-emisiones-de-co2-producidas-en-lasconstrucciones-de-andalucia-y-susimplicaciones-en-el-protocolode-kioto. Database date: 16/09/2010.

Received: October 11, 2011

Revised: October 22, 2011

Accepted: October 25, 2011

(C) Mercader Moyano et al.; Licensee Bentham Open.

This is an open access article licensed under the terms of the Creative Commons Attribution Non-Commercial License (http://creativecommons.org/licenses/by-nc/3.0/) which permits unrestricted, non-commercial use, distribution and reproduction in any medium, provided the work is properly cited. 